\title{
Interactions between Asphaltenes and a Model Demulsifier in Bulk and at an Interface Studied by Small-Angle Neutron Scattering (SANS) and Neutron Reflectometry
}

\author{
Kenneth D. Knudsen, Sébastien Simon,* Thomas Geue, Joshaniel F. K. Cooper, and Johan Sjöblom
}

Cite This: Energy Fuels 2020, 34, 6768-6779

Read Online

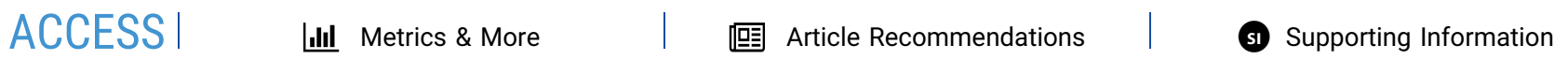

ABSTRACT: This article describes neutron reflectometry to probe the structure of the asphaltene layer adsorbed onto a hydrophilic silicon surface and the interactions between asphaltenes and a model demulsifier (pluronic). To start with, asphaltene nanoaggregation is studied in bulk by small-angle neutron scattering (SANS). In pure toluene, asphaltenes form nanoaggregates with sizes that are found to moderately increase when heptane is added. Then, the structure of the asphaltene layer onto a silicon surface is determined by neutron reflectometry. It is first shown that conclusive results on the structure of the adsorbed asphaltene layer can only be determined by varying the scattering length density of the solvent, i.e., by measuring reflectivity curves in various mixtures of $\mathrm{D}$ - and $\mathrm{H}$-toluene and by simultaneously fitting all the data sets. The asphaltene layer can be successfully modeled using a single layer; a two-layer model always converges with the second layer having zero thickness. This layer has a thickness of $51 \AA$, with a low solvation close to the silicon surface (estimated $\approx 29 \%$ ). The solvation increases with distance from the silicon oxide layer, reaching finally a value of $91 \%$. Small-angle neutron scattering data indicate that the thickness is close to twice the radius of gyration of asphaltene nanoaggregates in solution. This result indicates that the extent of the asphaltene layer is linked to its self-associative properties in bulk. Finally, using the results obtained by contrast matching to constrain the fitting, the influence of a model demulsifier (pluronic PE 8100) on the asphaltene layer is investigated. In the presence of pluronic, the layer does not protrude as far into the bulk (thickness is reduced) and becomes rougher due to the partial incorporation of pluronic.

\section{INTRODUCTION}

The production of crude oil is associated with the coproduction of important amounts of water. Indeed, in 2009 on a world basis, 250 million barrels of water was coproduced (water cut ca. 70\%) along with the 80 million barrels. ${ }^{1}$ This water is generally present as water-in-oil (w/o) emulsions. These emulsions need to be processed to obtain oil containing less than $0.5 \%$ water to be exported and water with a concentration of oil in the water phase lower than $30 \mathrm{ppm}$ to be discharged. The oil-water separation process is based on gravity difference between oil and water. It takes place in multistage gravity separators, which allows the sedimentation and the coalescence of water droplets. Various strategies can be implemented to speed up the separation: heating to reduce the viscosity of the oil phase and improving coalescence by either implementing electric fields (electrocoalescence ${ }^{2-4}$ ) and/or adding cocktails of chemicals named demulsifiers. ${ }^{5}$

Crude oil emulsions are stabilized by various crude oil components, $^{6}$ namely, asphaltenes, ${ }^{7,8}$ naphthenic acids, ${ }^{9-11}$ and resins, and also by inorganic particles ${ }^{12-14}$ (Pickering emulsions). In addition, there are interactions between these components. Asphaltenes and resins can adsorb onto solid particles modifying their wettability and their emulsionstabilizing properties. ${ }^{12,13}$ In principle, particles and other crude oil components could coadsorb at the liquid/liquid interface.

Asphaltenes are the most polar compounds present in crude oil. They are defined as the fraction of oil insoluble in $n$-alkanes such as $n$-pentane, $n$-hexane, and $n$-heptane and soluble in aromatic solvents such as toluene or xylene. ${ }^{6,15}$ Asphaltenes are mixtures of molecules differing in molecular weight and chemical structure. ${ }^{16,17}$ Fluorescence depolarization techniques, ${ }^{18-21}$ subsequently confirmed by mass spectrometry, ${ }^{22-24}$ have shown that typical mean molecular weights of asphaltenes are ca. $750 \mathrm{~g} \cdot \mathrm{mol}^{-1}$ with a factor of two in the width of the molecular weight distribution. Asphaltenes include significant amounts of heteroatoms (nitrogen, oxygen, and sulfur) and metals, the most abundant being iron, nickel, and vanadium. The presence of heteroatoms makes the asphaltenes relatively polar with the presence of functional groups like pyridine or pyrrole in the case of nitrogen ${ }^{25,26}$ and carboxylic acid, phenol, or ketone for oxygen. ${ }^{27}$ It has also been shown that asphaltenes are polyaromatic. Based on all the structural characterization results, different models have been suggested to represent an "average" asphaltene molecule: the archipelago and the continental models. $^{28}$ The latest published results, for instance, the direct visualization of asphaltene molecules by atomic force microscopy (AFM) and molecular orbital imaging using scanning tunneling microscopy (STM), ${ }^{29}$ seem to point

Received: November 3, 2019

Revised: April 14, 2020

Published: May 1, 2020 
toward the second. ${ }^{30}$ However, this predominance could be sample-dependent, as recently shown by Chacón-Patiño et al. ${ }^{31}$ using mass spectrometry techniques. In the continental model, asphaltenes are composed of a single polyaromatic ring with aliphatic and/or naphthenic substituents, while there are several polyaromatic rings linked together in the archipelago model.

Asphaltenes are prompt to self-associate in bulk both in model solvent and in crude oil. Two scales have to be considered. ${ }^{32}$ First, in good solvent conditions like toluene or xylene, asphaltenes form nanometer-sized aggregates, subsequently referred to as nanoaggregates, that are stable in time. If the solvent conditions get worse (by addition of a precipitant like an alkane for instance) and the precipitation onset is reached, asphaltenes start to flocculate or undergo a phase transition to form micrometer-sized flocs. ${ }^{33,34}$

Small-angle X-ray scattering (SAXS) and small-angle neutron scattering (SANS) are often used to study the nanoaggregate properties of asphaltenes in bulk since light scattering methods are not ideal due to the opacity of the solutions. Size and molecular weight of nanoaggregates have been determined by analyzing scattering curves at low scattering vector $Q$ using equations that do not assume any particular shape of the asphaltene nanoaggregates (Guinier or Zimm equation) or by fitting the entire curve assuming a shape of spheres or oblate or prolate cylinders. Despite the diversity of analysis methods, most SAXS and SANS studies converge on nanoaggregate sizes between ca. 2 and $10 \mathrm{~nm}$ depending on the origin of the asphaltenes, the nature of the solvent, and the temperature. $^{35-44}$

Different models have been proposed to describe the asphaltene nanoaggregation: the Yen model ${ }^{45}$ and its updated version, the Yen-Mullins model; ${ }^{30,46}$ the peptization model by Pfeiffer and Saal; ${ }^{47}$ and the application of fractal concepts. ${ }^{38,40}$ In the Yen-Mullins model, ${ }^{30,46} \mathrm{ca}$. six asphaltene molecules self-associate to form nanoaggregates by $\pi-\pi$ stacking of their polyaromatic parts. At higher concentrations, nanoaggregates form clusters again with small aggregation numbers. The study by Eyssautier et al. ${ }^{48}$ combining small-angle neutron scattering (SANS) and small-angle X-ray scattering (SAXS) describes asphaltene nanoaggregates as formed by the fractal aggregation of small core-shell disks. This study is consistent with the Yen-Mullins model. The aggregation extent seems to be a trade-off between attractive interactions $(\pi-\pi$ stacking, hydrogen bonds, ${ }^{49}$ etc.) and repulsions due to steric hindrance by aliphatic chains. ${ }^{50,51}$

The structure of the asphaltene layer on water droplets has been studied by small-angle neutron scattering using model systems by Jestin et al. ${ }^{52}$ and Verruto and Kilpatrick. ${ }^{53}$ These authors have managed to determine the values of the following parameters: the adsorbed amount at the interface $\approx 2 \mathrm{mg} / \mathrm{m}^{2}$, volume fraction of asphaltenes in the adsorbed layer $\approx 10-$ $30 \%$, and thickness of the adsorbed layer $\approx 10-15 \mathrm{~nm}$.

Demulsifiers are molecules designed to increase the oilwater separation rate. ${ }^{5}$ They entail a large variety of chemical structures ranked in 10 different chemical classes by Kelland. ${ }^{54}$ However, this author notes that most of the demulsifiers are nonionic polymers with molecular weight typically in the 2000-5000 $\mathrm{g} / \mathrm{mol}$ range even if some demulsifiers can be much bigger. Moreover, generally, demulsifiers contain polyalkoxylate chains like ethylene oxide (EO) and propylene oxide (PPO). Demulsifiers are generally injected at a dosage of a few tens of ppm in production facilities. The choice of the demulsifier for a specific oil field is still based on trial and error involving multiple bottle tests.

In order to obtain better knowledge about the mechanism of demulsification, in the present study, the structure of the asphaltene layer was determined at the silica/toluene interface by neutron reflectometry (NR). This setup was chosen in order to mimic the water-oil interface present in crude oil emulsions. Then, the interactions between asphaltenes and a model demulsifier (pluronic PE 8100) were studied with the same technique. The size of asphaltene aggregates dissolved in model organic solvents was also examined by small-angle neutron scattering (SANS) to determine the relationships between surface and bulk properties.

\section{EXPERIMENTAL SECTION}

2.1. Chemicals. Asphaltenes were obtained by precipitation from a Norwegian heavy crude oil. Briefly, $n$-hexane was added to the crude oil at a ratio of $40 \mathrm{~mL}$ hexane/g crude oil and stirred overnight. Then, the asphaltene was recovered after filtration using a $0.45 \mu \mathrm{m}$ HVLP (Millipore) membrane filter and dried in a nitrogen environment. The elemental composition of asphaltenes obtained from the same crude oil and the same procedure is presented in Subramanian et al. ${ }^{17}$ The flocculation onset of the asphaltenes was determined by optical microscopy to be comprised between $70 / 30$ and $60 / 40 \% \mathrm{v} / \mathrm{v} \mathrm{H}$ heptane/H-toluene at a concentration of $2 \mathrm{~g} / \mathrm{L}$ for $1 \mathrm{~h}$ and 1 day aged solutions. After 1 week, a few flocs are difficultly visible in $60 / 40 \% \mathrm{v} / \mathrm{v}$ $\mathrm{H}$-heptane/H-toluene indicating that the flocculation onset must be close to this value, while no floc is visible in $50 / 50 \% \mathrm{v} / \mathrm{v} \mathrm{H}$-heptane/ H-toluene.

Pluronic PE 8100 was obtained from BASF. Pluronic is a triblock copolymer $\mathrm{PEO}_{x}-\mathrm{PPO}_{y}-\mathrm{PEO}_{z}$ with a molecular weight of ca. $2600 \mathrm{~g} /$ mol and $10 \%$ PEO groups. ${ }^{55}$

Silicon wafers were obtained from two different providers: The experiments at Paul Scherrer Institute were performed using silicon wafers from SPM AG (Liechtenstein) of dimensions $100 \times 50 \times 10$ mm (DSP < $10 \AA)$. The silicon wafer used at the Rutherford Appleton Laboratory was from Crystran Limited (UK). It is a silicon block (111) of N-type of dimensions $80 \times 50 \times 15 \mathrm{~mm}$ (surface roughness, $\mathrm{Ra}<4 \AA$ ).

Silica QSX 303 crystals from Biolin Scientific were used for the QCM experiments.

Deuterated toluene ( $\geq 99.6$ atom \% D) was from Sigma-Aldrich, while deuterated heptane was from Chiron (Norway).

2.2. Preparation of Solutions and Surfaces. Asphaltene solutions were prepared by dissolving solid asphaltenes in deuterated and hydrogenated toluene. The solutions were then sonicated for half an hour and shaken overnight. Finally, the asphaltene solutions were mixed with heptane, toluene, and pluronic solutions in toluene to the desired mixture compositions.

The silicon wafers and QCM crystals were chemically handled before use to obtain a well-defined oxide layer at their surface with the following treatment. ${ }^{56}$ First, the wafers were thoroughly rinsed with Milli-Q water (Millipore) and treated with a solution composed of ammonia ( $30 \%$ solution), hydrogen peroxide (30\% solution), and Milli- $Q$ water (volume ratio $1: 1: 5$ ) at $75{ }^{\circ} \mathrm{C}$ for $15 \mathrm{~min}$. The crystals were then thoroughly rinsed with Milli- $\mathrm{Q}$ water and dried. For wafers that had already been used previously (except QCM crystals), they were first washed with $\mathrm{H}$-toluene and acetone and dried out before being treated with $\mathrm{NH}_{3} / \mathrm{H}_{2} \mathrm{O}_{2} / \mathrm{H}_{2} \mathrm{O}$.

2.3. Small-Angle Neutron Scattering (SANS). SANS measurements were used to determine the size of asphaltene aggregates. It is a technique that has also been applied before to characterize asphaltene samples (size, molecular weight, and shape ${ }^{36,39,44}$ ).

The SANS measurements were performed at the IFE facilities in Kjeller, Norway using the JEEP-II reactor. The samples were introduced in $2 \mathrm{~mm}$ Starna quartz cells and mounted in copper holders, keeping the temperature constant at $23{ }^{\circ} \mathrm{C}$. Two different detector distances were employed $(1.0 / 3.4 \mathrm{~m})$, as well as two different 

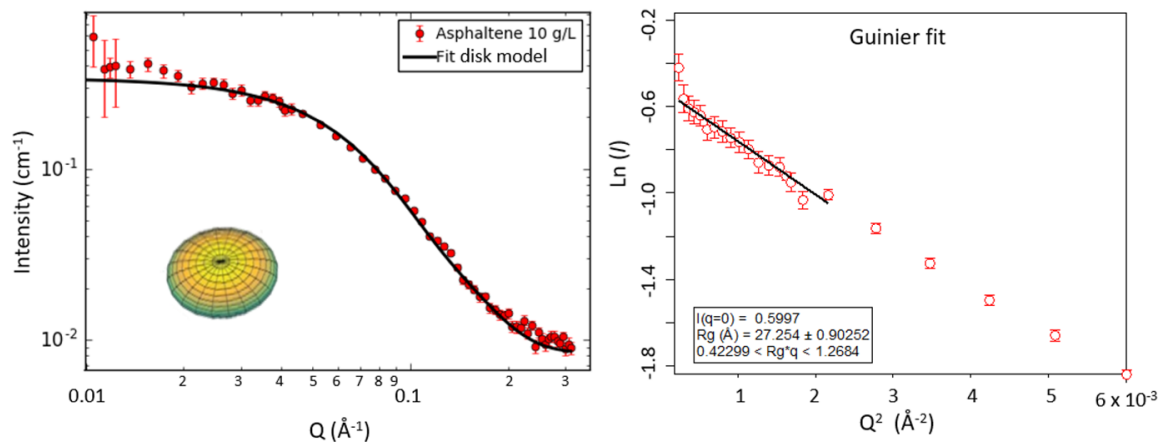

Figure 1. Determination of the nanoaggregate size of asphaltenes. (left) Scattering pattern and the fitting with a disk model; (right) using the Guinier fit with $\ln I(Q)$ as a function of $Q^{2}$. System: [Asphaltenes] $=10 \mathrm{~g} / \mathrm{L}$ in D-toluene.

wavelengths $(5.1 / 10.2 \AA)$, in order to obtain a wide $Q$ range. Here, $Q$ is given as $Q=(4 \pi / \lambda) \sin (\theta)$, with $\lambda$ being the neutron wavelength and $2 \theta$ the scattering angle. The transmission was measured separately, and the absolute scattering cross section $I(Q)\left(\mathrm{cm}^{-1}\right)$ of the samples was calculated by subtracting the contribution from the empty cell, solvent (mixture of deuterated heptane and toluene, same composition as the analyzed sample), and general background.

2.4. Neutron Reflectometry. Neutron reflectometry experiments were performed at two different neutron facilities: at the Paul Scherrer Institute-PSI (Switzerland) and at the ISIS Neutron and Muon Source (UK). First, experiments were performed at PSI in D-toluene and aimed to study the adsorption of asphaltenes and pluronic in Dtoluene. It was then realized, by analyzing PSI data, that it is necessary to measure the same system at various $\mathrm{D}$-toluene $/ \mathrm{H}$-toluene ratios to obtain more robust fitting of the data and clear conclusions. These measurements were performed at ISIS on asphaltene.

The purpose of the experiments, the experimental procedures, and the analysis of the experiments performed at the two institutes being different, they are presented separately. At PSI, the experiments were performed on the AMOR reflectometer. ${ }^{57} \mathrm{~A}$ cleaned wafer was installed into the cell, and up to $25 \mathrm{~mL}$ of solution to be analyzed was introduced. After plugging both ends of the flow line, the cell was installed in the reflectometer and aligned with the neutron beam. The measurements started 10 to $15 \mathrm{~min}$ after introduction of the solution. The temperature was kept constant at $23{ }^{\circ} \mathrm{C}$. At ISIS, the experiments were performed on the Offspec reflectometer. Only one silicon wafer was used in the entire campaign, and the alignment was only carried out one time with the cell filled with $\mathrm{D}$-toluene. The measurements were performed by exchanging the asphaltene solution previously in the cell by flowing through $17 \mathrm{~mL}$ of a new asphaltene solution at the same concentration $(2 \mathrm{~g} / \mathrm{L})$ with a different $\mathrm{D}$-toluene/H-toluene ratio to vary the contrast. The last $3 \mathrm{~mL}$ exchanged was recovered, and its density was measured at $20^{\circ} \mathrm{C}$ by an Anton Paar DMA 4100 densitometer to make sure that the exchange was complete. The reflected intensity was measured at three angles $\left(0.5,1.3\right.$, and $\left.2^{\circ}\right)$ using a wavelength band of $1-14 \AA$.

The analysis was performed by means of the Motofit routines ${ }^{58}$ implemented into the IGOR programming environment ${ }^{59}$ as well as the GenX software. ${ }^{60}$ The latter was particularly useful for linking several coupled parameters during the contrast variation series. The appropriate $\mathrm{d} Q / Q$ resolution given by the experimental setup was entered for each case in order to properly account for instrumental broadening. The Levenberg-Marquardt algorithm (Motofit) and the so-called differential evolution algorithm (GenX) were employed in the least-square analysis, and in all cases, the $\chi^{2}$ values were followed to ensure convergence.

The reflectivity data were fitted by a model that is composed of several layers, each one characterized by a certain SLD value, thickness, and roughness. An experimentally found gradual change in the SLD between two layers (after taking into account the minor profile broadening originating from the reflectometer itself) can be described by introducing a certain roughness since that will modify the reflectivity of the interface. The roughness was accounted for mathematically by a function with a sigmoidal shape in terms of position $(z)$, the so-called error function (cf. eq 1 ), and the numerical value is simply defined as the width (i.e., standard deviation) of this function. ${ }^{61}$

$$
\operatorname{erf}(z)=\frac{2}{\sqrt{ } \pi} \int_{0}^{z} \mathrm{e}^{-t^{2}} \mathrm{~d} t
$$

It is important to note that the term "roughness" incorporates also a situation with interdiffusion between layers, i.e., when there is a transition region where one phase gradually diffuses into the other. Pure roughness (i.e., a sharp but geometrically nonflat transition between materials) and interdiffusion (nonsharp but flat transition region) are not distinguishable in specular reflectometry, thus also not in this study, and can both be described by the error function mentioned above (cf. ref 62). The fitting procedure consisted of finding the numerical values of the thickness and roughness parameters that best explained the experimentally measured reflectivity, with the relative contribution of pure roughness and interdiffusion (if both are present) being unknown. It is also relevant to note that since the roughness is mathematically defined as the standard deviation of the error function, the total width of a transition region in the SLD diagram, as judged by simple visual inspection, will be larger than the roughness value itself. The difference will be approximately a factor of 3 . Furthermore, the thickness of a layer (e.g., asphaltene) is defined as the distance between the midpoint in the transition region on each side of the layer, i.e., from the midpoint of the $\mathrm{SiO}_{2}$-asphaltene interface to the midpoint of the asphaltenesolvent interface. This definition has the consequence that for a thin layer with significant roughness on each side, the two transition regions will approach each other so that one may not observe a region with a constant SLD value characteristic of that material (cf. theoretical values in Table 3). The result will rather be a continuously varying SLD profile, representing the best global fit to the reflectivity data.

2.5. Quartz Crystal Microbalance (QCM). Extra experiments were performed by QCM to determine the adsorbed amount of asphaltenes, pluronic, and mixture of asphaltenes + pluronic.

Experiments were performed using the single sensor microbalance system Q-sense E1 from Biolin Scientific at $20^{\circ} \mathrm{C}$. First, pure toluene was injected until a stable baseline was obtained. The solution to be analyzed was then injected into the chamber and left to rest for $1 \mathrm{~h}$. A desorption study was done by subsequently injecting pure toluene. The QCM apparatus measures the variation of the oscillation frequency $\Delta f$ due to the adsorption for various overtone numbers $n$. The adsorbed amount $\Gamma$ was calculated using the Sauerbrey equation $^{63}$

$$
\Delta \Gamma=-\frac{\rho_{\mathrm{q}} t_{\mathrm{q}}}{f_{0} n} \Delta f=-\frac{\rho_{\mathrm{q}} v_{\mathrm{q}}}{2 f_{0}^{2} n} \Delta f=-\frac{C}{n} \Delta f
$$

where $\rho_{\mathrm{q}}\left(=2648 \mathrm{~kg} / \mathrm{m}^{3}\right)$ and $t_{\mathrm{q}}(=0.3 \mathrm{~mm})$ are the mass density and thickness of the crystal, $v_{\mathrm{q}}(=3340 \mathrm{~m} / \mathrm{s})$ is the shear wave velocity in 
Table 1. Size of Asphaltene Nanoaggregates Calculated with the Guinier and Disk Model Equations (Equations 3 and 4 ) and Measured in Various Solvents and Concentrations ${ }^{a}$

\begin{tabular}{|c|c|c|c|c|c|c|}
\hline \multirow[b]{2}{*}{ [asphaltenes] (g/L) } & \multirow[b]{2}{*}{ solvent } & \multirow[b]{2}{*}{ Guinier Rg ( } & \multicolumn{2}{|c|}{ disk model } & \multirow[b]{2}{*}{$M_{\mathrm{w}}(\mathrm{g} / \mathrm{mol})$} & \multirow[b]{2}{*}{$N_{\text {agg }}$} \\
\hline & & & radius $(\AA)$ & height $(\AA)$ & & \\
\hline 10 & D-toluene & $28.7 \pm 1.5$ & $31.0 \pm 1$ & $20.6 \pm 1$ & $14,400 \pm 400$ & $19 \pm 1$ \\
\hline 10 & $25 / 75 \% \mathrm{v} / \mathrm{v}$ D-heptane/D-toluene & $28.3 \pm 1.5$ & $31.8 \pm 1$ & $21.2 \pm 1$ & $13,700 \pm 400$ & $18 \pm 1$ \\
\hline 10 & $50 / 50 \% \mathrm{v} / \mathrm{v} \mathrm{D}$-heptane/D-toluene & $35.3 \pm 1.5$ & $39.2 \pm 1$ & $21.1 \pm 1$ & $25,300 \pm 500$ & $34 \pm 1$ \\
\hline 2.5 & D-toluene & $31.5 \pm 2$ & $\mathrm{u}$ & $\mathrm{u}$ & $\mathrm{u}$ & $\mathrm{u}$ \\
\hline
\end{tabular}

$a_{\mathrm{u}}$ : Not reported due to large uncertainties in the disk model. Also shown is the molecular weight calculated as explained in the text and the corresponding aggregation number for the nanoaggregates.

quartz, and $f_{0}(=5 \mathrm{MHz})$ is the fundamental frequency of the crystal. The constant $C$ equals $0.177 \mathrm{mg} / \mathrm{m}^{2} \mathrm{~Hz}$.

\section{RESULTS AND DISCUSSION}

3.1. Bulk Nanoaggregation Studied by SANS. The selfassociation properties of asphaltenes in bulk are first analyzed. These properties will be compared with the structure of the asphaltene layer presented in section 3.2.3.

3.1.1. Nanoaggregation in Pure D-Toluene. This section presents the result of the characterization of nanoaggregates formed in solution by asphaltenes in a good solvent (Dtoluene).

Figure 1 shows the scattering pattern of a solution of $10 \mathrm{~g} / \mathrm{L}$ asphaltenes in D-toluene. The same plot for a less concentrated solution $(2.5 \mathrm{~g} / \mathrm{L})$ is presented in the Supporting Information (Figure S1). These concentrations were chosen to obtain an adequate signal-to-noise ratio, and they are relatively close to the concentration used in neutron reflectometry experiments $(2 \mathrm{~g} / \mathrm{L})$. The pattern is typical of the scattering of asphaltene nanoaggregates ${ }^{36,43}$ with a plateau at low $Q$ and a decrease of the intensity at higher $Q$ values. Two methods were used to calculate the size of asphaltene nanoaggregates: First, the Guinier fit (eq 3) valid at low $Q(Q \times \operatorname{Rg}<1)$ allows us to determine the radius of gyration $\mathrm{Rg}$ by plotting $\ln I(Q)$ as a function of $Q^{2}$ This method is independent of the shape of the asphaltene nanoaggregates.

$$
I(Q)=I_{0} \exp \left(-\frac{\mathrm{Rg}^{2}}{3} \times Q^{2}\right)
$$

Here, $Q$ is the absolute value of the scattering vector as defined previously.

Second, the entire scattering pattern was fitted with a disk model (flat cylinder) as defined in eq $4 .{ }^{64} P(Q)$ is the form factor, which at low concentrations is proportional to the intensity.

$$
P(Q)=\frac{\text { scale }}{V} \int_{0}^{\pi / 2} F^{2}(Q, \alpha) \sin \alpha \mathrm{d} \alpha+\text { background }
$$

where "scale" is a constant and $F^{2}(\mathrm{Q} \alpha)$ is the squared value of the scattering amplitude given by

$$
F(Q, \alpha)=2(\Delta \rho) V \frac{\sin \left(\frac{1}{2} Q L \cos \alpha\right)}{\frac{1}{2} Q L \cos \alpha} \frac{J_{1}(Q R \sin \alpha)}{Q R \sin \alpha}
$$

Here, $\mathrm{R}$ is the disk radius, $L$ the disk height, and $V$ is the disk volume given by $\pi R^{2} L$. The parameter $\alpha$ is the angle between the disk axis and the $Q$ vector.
This model allows us to obtain both the radius and the height of the disk. It has for instance been used by Gawrys and Kilpatrick in their studies of asphaltenes. ${ }^{65,66}$ In particular, these authors ${ }^{65}$ have shown by analyzing asphaltenes from 4 different crude oils that the shape of asphaltenes is best fitted by a polydisperse radius oblate cylinder model. Figure 1 indicates that the disk models fit well with the SANS intensity profile. This correspondence does not exclude other possible shapes; for instance, it might also be possible to fit these data with nearly equally good results by assuming spherical particles with a broad size distribution, and different shapes have been reported in the literature. ${ }^{36}$ However, model fitting with this disk model will allow us to systematically compare the sizes of asphaltene nanoaggregates in different media. In this work, the structure factor was assumed equal to 1 (insignificant particleparticle interactions) due to the relatively low asphaltene concentration in solution $(2.5$ and $10 \mathrm{~g} / \mathrm{L})$ and the observation that we do not find any sign of depression of the scattering curve characteristic for a system with significant particleparticle interactions.

The radius of gyration, disk radius, and height for a $10 \mathrm{~g} / \mathrm{L}$ asphaltene solution in D-toluene determined from the two methods are reported in Table 1. The two methods agree on an asphaltene nanoaggregate radius close to $3 \mathrm{~nm}$, which is in the lower range of typical values reported in the literature. ${ }^{35-44}$ The size extracted at $2.5 \mathrm{~g} / \mathrm{L}$, also shown in Table 1 , is found similar to that at $10 \mathrm{~g} / \mathrm{L}$ within the error bars. The latter is larger for the $2.5 \mathrm{~g} / \mathrm{L}$ sample due to the lower concentration, and consequently, the signal is weaker. Results obtained with the disk model are not reported for the $2.5 \mathrm{~g} / \mathrm{L}$ sample since the uncertainties in the parameters determined with this model are quite large owing to the weaker signal compared with data obtained at $10 \mathrm{~g} / \mathrm{L}$.

3.1.2. Influence of Asphaltene Solvency. The size of asphaltene nanoaggregates was determined in different solvency conditions, i.e., by adding different amounts of Dheptane but still below the precipitation onset. ${ }^{49}$ The scattering patterns of $10 \mathrm{~g} / \mathrm{L}$ asphaltenes in D-toluene and in $25 / 75$ and $50 / 50 \%$ v/v D-heptane/D-toluene mixed solvents are presented in Figure 2. It can be seen that the scattering pattern is similar in D-toluene and in 25/75\% v/v D-heptane/ $\mathrm{D}$-toluene, which means that the nanoaggregates are similar in both media. On the contrary, in the presence of $50 \% \mathrm{D}$ heptane, the scattering intensity significantly increases, meaning that the asphaltene nanoaggregates have grown in size. The superimposition of scattered intensity in the high- $Q$ region $(Q$ $>0.1 \AA$ ), in pure toluene and in the mixture of toluene and heptane, indicates that the internal structure of the asphaltene aggregates does not depend on the solvent. The sizes extracted from the scattering patterns and summarized in Table 1 confirm the trend observed in Figure 2. Indeed, the radius of 


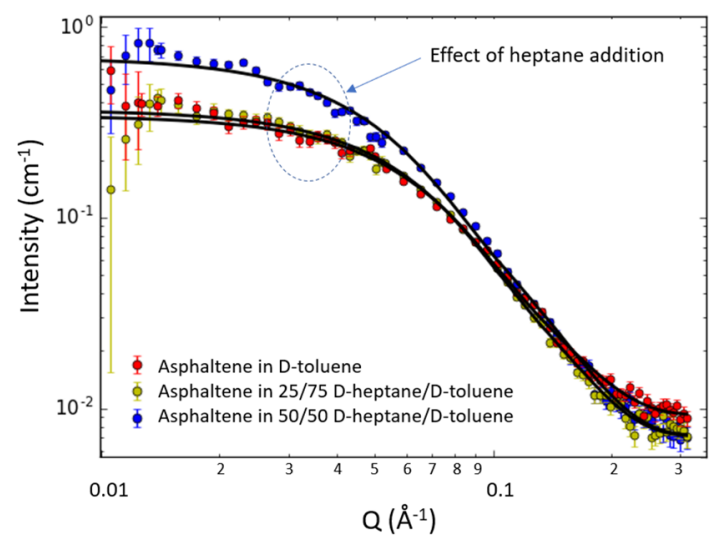

Figure 2. Influence of D-heptane on the scattering pattern of asphaltenes. System: [Asphaltenes] $=10 \mathrm{~g} / \mathrm{L}$ in D-toluene, $25 / 75 \% \mathrm{v} /$ $\mathrm{v}$, and $50 / 50 \% \mathrm{v} / \mathrm{v}$ D-heptane/D-toluene mixed solvents. The contribution of solvents has been subtracted from the intensities.

gyration of asphaltene nanoaggregates remains nearly constant in the presence of $25 \% \mathrm{v} / \mathrm{v} \mathrm{D}$-heptane (28.7 $\AA$ in D-toluene vs. $28.3 \AA$ in $25 / 75 \%$ v/v D-heptane/D-toluene) and significantly increases in 50\% v/v D-heptane (35.3 $\AA$ ). However, even if it increases, the radius is still in the nanometer range; thus, only moderate additional aggregation takes place. Similar observations can be done with the sizes calculated from the disk model, especially by looking at the radius values. These results are consistent with the observations by Fenistein et al., ${ }^{39}$ Spiecker et al. (below the precipitation onset), ${ }^{41}$ and Hoepfner et al. ${ }^{67,68}$ For instance, Hoepfner et al. ${ }^{68}$ have observed that the radius of gyration and the molecular weight of asphaltenes from four different oils in toluene-heptane solvent increase with the heptane content up to a maximum and then decrease. $\mathrm{Rg}$ values vary from $\approx 5$ to $15 \mathrm{~nm}$ in pure toluene to $\approx 7$ to 42 $\mathrm{nm}$ in toluene-heptane mixtures depending on the asphaltene sample.

In Table 1 are also shown the molecular weights $\left(M_{\mathrm{w}}\right)$ of the nanoaggregates, calculated from the relationship between $M_{\mathrm{w}}$ and the asymptotic crossing with the intensity axis, as previously used in our work on tetrameric acid. ${ }^{69}$ The crossing will also be proportional to the square of the difference in scattering length density between the particle and the solvent. For this calculation, the scattering length densities for the asphaltene $\left(1.32 \times 10^{-6} \AA^{-2}\right)$, D-toluene $\left(5.66 \times 10^{-6} \AA^{-2}\right)$, and D-heptane $\left(6.30 \times 10^{-6} \AA^{-2}\right)$ were therefore used, together with the specific weight of $1.15 \mathrm{~g} / \mathrm{cm}^{3}$ for asphaltene. From the molecular weight of the aggregate, the aggregation number $\left(N_{\mathrm{agg}}\right)$ can also be calculated given the molecular weight of an asphaltene molecule. Using the value of $750 \mathrm{~g} /$ mol determined by Groenzin and Mullins, ${ }^{19,20}$ we find that $N_{\text {agg }}$ increases from ca. 19 in D-toluene to 34 in the $50 / 50 \mathrm{D}$ heptane/D-toluene mixture.

3.2. Asphaltene Conformation at Solid Surfaces. 3.2.1. Determination of Adsorbed Amounts Using QCM. QCM is a classical technique to characterize adsorption of asphaltenes onto solid surfaces. This technique allows us to determine the adsorbed amount, a parameter that can also be determined from the analysis of neutron reflectometry data. Consequently, values obtained from QCM will be used to test the validity of the neutron reflectometry results.

Table 2 presents the adsorbed mass after $1 \mathrm{~h}$ adsorption, $\Gamma_{\text {ads }}$, and after $30 \mathrm{~min}$ of desorption in toluene, $\Gamma_{\text {des }}$, i.e., the amount of asphaltenes still present on the crystal after
Table 2. Determination of Adsorbed Amount $(n=5)$ onto the Silica Surface by QCM after $1 \mathrm{~h}$ of Adsorption, $\Gamma_{\text {ads, }}$ Followed by 30 min of Desorption with Pure Toluene, $\Gamma_{\text {des }}{ }^{a}$

\begin{tabular}{|c|c|c|}
\hline system & $\Gamma_{\text {ads }}\left(\mathrm{mg} / \mathrm{m}^{2}\right)$ & $\Gamma_{\text {des }}\left(\mathrm{mg} / \mathrm{m}^{2}\right)$ \\
\hline pluronic $(0.1 \mathrm{~g} / \mathrm{L})$ & $1.57 \pm 0.12$ & $1.06 \pm 0.08$ \\
\hline asphaltenes $(2 \mathrm{~g} / \mathrm{L})$ & $3.28 \pm 0.18$ & $2.56 \pm 0.23$ \\
\hline pluronic $(0.1 \mathrm{~g} / \mathrm{L})+$ asphaltenes $(2 \mathrm{~g} / \mathrm{L})$ & $2.65 \pm 0.18$ & $1.98 \pm 0.13$ \\
\hline
\end{tabular}

replacing the asphaltene solution in the cell by pure toluene. The amount of asphaltene adsorbed onto silica surfaces (3.28 $\left.\mathrm{mg} / \mathrm{m}^{2}\right)$ and the desorption $\left(19 \%\right.$, based on $\Gamma_{\text {des }}=2.65 \mathrm{mg} /$ $\mathrm{m}^{2}$ ) are typical of values found in the case of adsorption of asphaltenes in good solvents like toluene or xylene onto polar surfaces. ${ }^{16,70}$ The pluronic adsorbed amount $\left(1.57 \mathrm{mg} / \mathrm{m}^{2}\right)$ is significantly lower than for asphaltenes. The value is, however, significantly higher than that measured by the depletion method on silica particles by Shar et al. ${ }^{71}$ These authors found values between 0.06 and $0.235 \mathrm{mg} / \mathrm{m}^{2}$ depending on the pluronic structure, but the solvent was different (water), which could explain the difference in the extent of adsorption.

When asphaltenes and pluronic are present in the same solution, the extent of adsorption is intermediate between pure pluronic and pure asphaltenes, meaning that the adsorbed layer is composed of a mixture of asphaltenes and pluronic. Unfortunately, it is not possible to determine the relative contribution of the two compounds from QCM data.

3.2.2. Neutron Reflectometry Study. In this section, the asphaltene layer is studied by neutron reflectometry. Neutron reflectometry is a powerful technique to determine the layer structure on flat surfaces. To our knowledge, this technique has only been applied two times previously to characterize asphaltene. Jouault et al. ${ }^{72}$ have studied the influence of the solvent composition on the adsorption of asphaltenes onto hydrophilic and hydrophobic silicon wafers, while Corvis et al. ${ }^{73}$ have determined the influence of the shear rate on the adsorption of asphaltenes.

Two neutron reflectometry measurement series were performed with different objectives: The internal structure of the asphaltene layer was determined by varying the scattering length density of the solvent (section 3.2.3) through measurements at RAL, and the influence of a model demulsifier (pluronic PE 8100) on the adsorption of asphaltenes was determined via measurements at PSI (section 3.2.4).

The analysis of the data was performed by using the scattering length densities summarized in Table 3. The scattering length density (SLD), which determines the neutron scattering contrast, is given by the expression SLD $=(1 /$ $\left.v_{\mathrm{m}}\right) \Sigma b_{i}$, where $b_{i}$ is the coherent scattering length of a specific

Table 3. Scattering Length Densities of the Materials Investigated

\begin{tabular}{lc}
\multicolumn{1}{c}{ material } & $\mathrm{SLD}\left(10^{-6} \AA^{-2}\right)$ \\
D-toluene & 5.66 \\
$\mathrm{H}$-toluene & 0.94 \\
$\mathrm{SiO}_{2}$ & 3.47 \\
$\mathrm{Si}$ & 2.07 \\
asphaltenes & 1.32 \\
pluronic & $\sim 0.5$
\end{tabular}


atom in a molecule and $v_{\mathrm{m}}$ the molecular volume. The SLD of asphaltenes was calculated from its elemental composition and density. This density $\left(1.154 \mathrm{~g} / \mathrm{cm}^{3}\right)$ was determined by extrapolating to $100 \%$ asphaltenes the variations of $1 /$ density of asphaltene solutions in xylene measured with a densitometer DMA 5000 (Anton Paar).

3.2.3. Conformation of Asphaltenes Determined by Contrast Variations. The first part of the neutron analysis consisted of analyzing the data obtained by the contrast variation method used at RAL. The constraints on fitting of multiple curves measured on the same system but at various $\mathrm{D}$ toluene/H-toluene ratios allowed us to obtain a robust determination of the properties of the interface. The procedure was confirmed by observing that the fitting converged to the same parameters independent of the initial guess.

The contrast variation method consists of determining the reflectivity curves of the asphaltene layer by varying the contrast between asphaltenes and the solvent, i.e., by changing the $\mathrm{D}$-toluene/H-toluene ratio. In practice, the procedure used was to inject into the silicon wafer-containing cell asphaltene solutions at the same concentration but with different $\mathrm{D}$ toluene/H-toluene ratios. The injection procedure was checked by measuring the density of the solution recovered at the end of the exchange period $d_{\mathrm{m}}$. Its mass fraction in Dtoluene $\phi_{\mathrm{m}-\mathrm{D} \text {-tol }}$ was calculated from $d_{\mathrm{m}}$ and the density of pure D-toluene $d_{\mathrm{D} \text {-tol }}$ and H-toluene $d_{\mathrm{H} \text {-tol }}$ measured beforehand using the relationship

$$
\phi_{\mathrm{m}-\mathrm{D}-\mathrm{tol}}=\frac{\frac{1}{d_{\mathrm{m}}}-\frac{1}{d_{\mathrm{H}-\mathrm{tol}}}}{\frac{1}{d_{\mathrm{D}-\mathrm{tol}}}-\frac{1}{d_{\mathrm{H}-\mathrm{tol}}}}
$$

The mass fraction in D-toluene calculated by means of eq 6 corresponded exactly to the prepared solutions (maximum difference in mass fraction of $7 \times 10^{-3}$ ), which validates the exchange procedure.

The reflectivity curves for pure D-toluene and solutions of asphaltenes $(2 \mathrm{~g} / \mathrm{L})$ in mixtures of $\mathrm{D}$-toluene and $\mathrm{H}$-toluene are presented in Figure 3, given as logarithm of $R Q^{4}$ as a

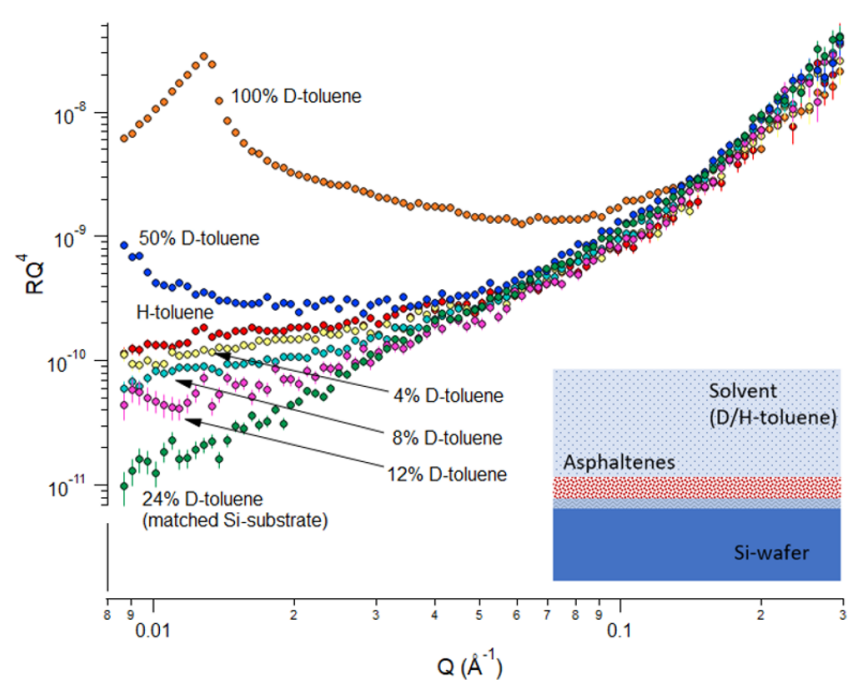

Figure 3. Reflectivity curves plotted in the form of $R Q^{4}$ as a function of $Q$ for pure solutions of asphaltenes $(2 \mathrm{~g} / \mathrm{L})$ in mixtures of $D$ toluene and $\mathrm{H}$-toluene. The volume fraction in $\mathrm{D}$-toluene is indicated on the curves. The data has been normalized but not backgroundsubtracted. function of $Q$. This representation is sometimes useful for neutron reflectivity as it allows us to visualize better the differences between systems, which can otherwise be difficult owing to the fast $Q^{-4}$ decay of the Fresnel reflectivity of the pure silicon/deuterated solvent interface.

The reflectivity of asphaltene solutions with a specific Dtoluene/H-toluene volume ratio depends principally on the scattering length density difference between the silicon layer ( SLD $=2.07 \times 10^{-6} \AA^{-2}$ ) and the solvent. The overall reflectivity is at its lowest for $24 \% \mathrm{v} / \mathrm{v}$ D-toluene when the SLD of the solvent and the silicon layer matches. The reflectivity is at its highest in pure $\mathrm{D}$-toluene since the contrast is maximum between the silicon layer and the solvent (Table 3).

The analysis of the data first started by determining the characteristics of the oxide layer on top of silicon. The analysis was performed by fitting the reflectivity curves of the silicon wafer measured in pure D-toluene in the absence of asphaltenes (see inset in Figure 4). In this situation, the reflectivity curve allows us to determine the thickness and the roughness of the silicon oxide layer.

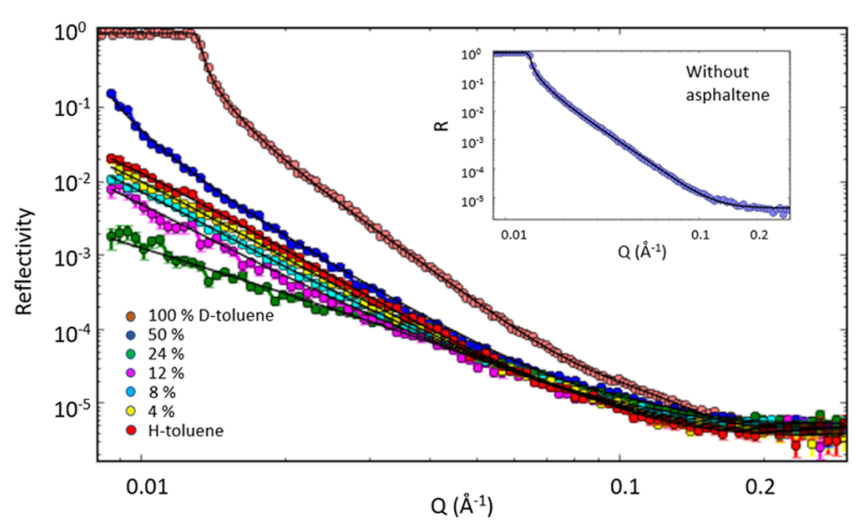

Figure 4. Reflectivity curves in the form of $\log R$ vs. $\log Q$ as a function of $Q$ for solutions of asphaltenes $(2 \mathrm{~g} / \mathrm{L})$ in mixtures of $D$ toluene and $\mathrm{H}$-toluene. The volume fraction in $\mathrm{D}$-toluene for the different samples is indicated. The continuous lines represent the model fits. The inset is the reflectivity data and model fit for the sample without asphaltene, i.e., Si wafer and D-toluene only. The data has been normalized but not background-subtracted. The model curves include background values used in the fitting.

The obtained value of $13 \AA$ for the thickness is typical of values found by other research groups for similar silicon oxide layers ${ }^{72,74,75}$ even if the oxidative treatment can be different (sulfuric acid and hydrogen peroxide for Jouault et al. or no surface treatment for Penfold et al.). The roughness was found to be $10 \AA$ for this system, also in the range typically found by others. Note that this corresponds to the roughness at the $\mathrm{SiO}_{2}$ /asphaltene interface when asphaltene is present in the sample cell. These values were employed as starting inputs in the model used to fit the reflectivity curves in the presence of asphaltenes and/or pluronic. There is also a small roughness for the pure silicon below the oxide layer. The roughness was fixed to a value of $3 \AA$, in accordance with specifications provided by the manufacturer. It should be noted that for relatively thin layers of adsorbed material, as expected in the present case for asphaltene, a correct determination of the properties of the $\mathrm{SiO}_{2}$ layer is critical for the evaluation of the thickness and roughness of the adsorbed layer since the final result will be very sensitive to the $\mathrm{SiO}_{2}$ parameters. This 
Table 4. Thickness, Roughness, and the Degree of Solvent Penetration for the Adsorbed Asphaltene $(2 \mathrm{~g} / \mathrm{L})^{a}$

$\begin{array}{ccccc}\text { asphaltene thickness } & \text { asphaltene roughness } & \text { solvation } & \mathrm{SiO}_{2} \text { thickness } & \mathrm{SiO}_{2} \text { roughness } \\ 51.4 \pm 1 \AA & 7.3 \pm 0.5 \AA & 91 \pm 1 \% & 13.3 \pm 0.5 \AA & 10.1 \pm 0.5 \AA\end{array}$

${ }^{a}$ Values for the $\mathrm{SiO}_{2}$ layer are also given. The figure of merit (FOM) for the simultaneous fitting was 0.034 .

sensitivity is due to the fact that the different contributions may be of similar size and are convoluted in the final scattering pattern.

A simultaneous fit of all the data sets that contained asphaltene $(2 \mathrm{~g} / \mathrm{L})$ with different $\mathrm{D}$-toluene/H-toluene ratios was made using the GenX platform, coupling together the parameters that were unchanged while varying the SLD values as given by the exact $\mathrm{D} / \mathrm{H}$ ratios for the solutions. The latter was determined via the known SLD values for D-toluene (5.66 $\left.\times 10^{-6} \AA^{-2}\right)$ and pure H-toluene $\left(0.94 \times 10^{-6} \AA^{-2}\right)$. In this manner, we could strongly constrain the parameters and avoid false minima in the fitting. Note also that since we had previously determined the chemical composition of this asphaltene by elemental analysis, we could fix the SLD of asphaltene to the calculated value of $1.32 \times 10^{-6} \AA^{-2}$. This approach allowed us to also determine accurately the degree of solvent penetration into the asphaltene (solvation). The fitted data are shown in Figure 4, with the numerical results in Table 4. Here, the values of thickness and roughness for the silicon oxide layer are also included.

The thickness we find ( $51 \AA$ ) corresponds quite well with the diameter found earlier from bulk measurements (with SANS) on these samples, where the nanoaggregate radius was found to be ca. $30 \AA$ and thus an approximate diameter of 60 $\AA$. However, the value is a bit lower, and this might be expected if there is a slight compression of the nanoaggregates due to the adherence to the hydrophilic surface. Jestin et al. ${ }^{52}$ also found by SANS that the asphaltene layer stabilizing waterin-toluene emulsions has a thickness that is very close to twice the radius of gyration of the aggregates in solution (for asphaltenes respectively precipitated in pentane, heptane, and octane, the radius of gyration are 66,84 , and $106 \AA$ and the thicknesses are 113,135 , and $149 \AA$ ). This relationship could mean that the extent of the asphaltene layer is linked to its selfassociative properties in bulk. The thickness found in the present study is lower than the values obtained by Jouault et al. and Corvis et al. ${ }^{72,73}$ from neutron reflectometry (62-87 $\AA$ depending on the resin content in the asphaltene sample). The thickness is also lower than values found by SANS in the model w/o emulsions $(100-150 \AA) \cdot{ }^{52,53}$ Adsorbed layer thicknesses deduced from surface-force-apparatus (SFA) measurement on bitumen asphaltene adsorbing onto silica surfaces in toluene are also higher. Indeed, Wang et al. ${ }^{76}$ found that the thickness (half the hard-wall distance value) of the asphaltene layer increases from $\approx 60-75 \AA$ to $300 \AA$ after respectively $2 \mathrm{~h}$ and $20 \mathrm{~h}$ of adsorption. Sztukowski et al. ${ }^{77}$ have studied the adsorption of asphaltenes onto water droplets by measuring the variations of the asphaltene adsorbed amount on water droplets and the molar mass of asphaltene aggregates in solution as a function of asphaltene concentration. They conclude that asphaltenes form aggregate monolayers at the liquid/liquid interface. They also calculated asphaltene film thickness values ranging from 20 to $90 \AA$ by assuming a cylindrical shape for adsorbed asphaltene molecules.

The difference between thickness values could perhaps be linked to the variability in asphaltene structure with their origin and their preparation method (presence of resins). In general, all asphaltenes present similar behavior/properties (nanoaggregation, flocculation, and adsorption), but the extent of these properties depends on their origin. For instance, Simon et al. have reported large variations of asphaltene nanoaggregate size in bulk depending on the crude oil origin, the preparation method ( $n$-alkane used), and the solvent. ${ }^{40}$

The roughness of the asphaltene layer toward the solvent was found to be $7.3 \AA$. This value is relatively low, but it could still indicate a slight irregularity over the surface or regions of dangling chains into the solvent.

It is interesting to note that the solvation is found to be very high, i.e., $91 \%$. This value is, however, in line with the values reported by Jestin et al. ${ }^{52}$ and Verruto and Kilpatrick ${ }^{53}$ in their characterizations of the asphaltene layers around water droplets by SANS, where asphaltene volume fractions of 10$20 \%$ are mentioned. However, one can gain a bit more information by plotting the calculated SLD profile versus distance. This plot is shown in Figure 5 for the case of

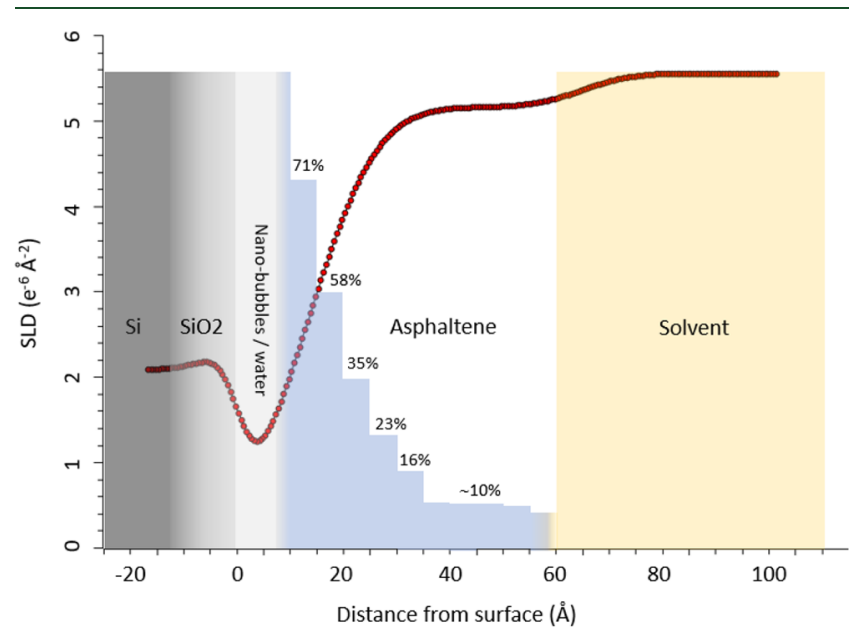

Figure 5. SLD profile for asphaltene in D-toluene as a function of distance from the silicon surface. The region named with each component in the figure is determined by the midpoints of the transitions between the neighboring layers, according to the definition in the fitting algorithm. An estimate of the amount of asphaltene (with respect to solvent) based on the SLD value at different distances is shown as vertical bars.

asphaltene in pure D-toluene. The main part of the asphaltene region is seen to have an SLD value slightly above 5, corresponding to a solvation of around $90 \%$ as mentioned above, and thus an asphaltene concentration of about $10 \%$. However, the SLD value is seen to drop considerably as one approaches the $\mathrm{SiO}_{2}$ surface, which is equivalent to a lower degree of solvation. The percentage of asphaltene can be estimated via linear interpolation between the value of pure asphaltene $\left(\mathrm{SLD}=1.32 \times 10^{-6} \AA^{-2}\right)$ and that of pure $\mathrm{D}$ toluene $\left(\mathrm{SLD}=5.66 \times 10^{-6} \AA^{-2}\right)$, which leads to an approximate asphaltene concentration of $71 \%$ (i.e., $29 \%$ solvation) for the region closest to the $\mathrm{SiO}_{2}$ surface. These results therefore indicate that there is a significant reduction in asphaltene solvation at the first $15-20 \AA$ from the surface. 
Note, however, that this estimate is based on the somewhat simplistic picture of the asphaltene layer starting at the position where the SLD has reached the value referred to above for pure asphaltene. The named regions correspond to the thicknesses found for each layer $\left(\mathrm{SiO}_{2}\right.$ and asphaltene). In practice, the interfaces are governed by the surface roughness in the model. The values noted for the asphaltene concentration are therefore rough indications, where the main point is rather the tendency of a low solvation near the surface and gradually increasing solvation away from the surface. Another point to mention is that within the experimental error of the data, it would be possible to assume another mathematical function (e.g., nonsmooth or nonsigmoidal) to represent the interface region with similar final $\chi^{2}$ values for the fitting. However, the information content of a reflectivity experiment is generally insufficient to divert from the established mathematical presentation of surface roughness that gives the transition region in the diagram. In summary, this means that there is a significant uncertainty with the local asphaltene concentrations shown in Figure 5. The amount is difficult to calculate but is likely on the order of $\pm 5 \%$ or more. This value is a rough estimate made by following the displacement of the SLD curve when entering different values for the thickness of the interface zone (roughness) between the asphaltene and the $\mathrm{SiO}_{2}$ surface. A $50 \%$ change in the roughness in both directions from the fitted value produced a displacement in the SLD curve corresponding to a 5\% change in the asphaltene concentration at a position halfway into the asphaltene layer.

One slightly surprising feature of the SLD curves is the dip in SLD outside the layer that we have designated $\mathrm{SiO}_{2}$. In neutron reflectivity, one does not obtain atomic information; thus, the designation $\mathrm{SiO}_{2}$ is solely a label. However, we do expect a layer since a $\mathrm{Si}(111)$ surface is not stable in air, and we generally see a native oxide layer forming, which is around 10-30 A on a silicon surface. This layer would, however, have a higher SLD than bulk Si. The observed low SLD value thus deserves some consideration. Anecdotally, such a layer is not unheard of when investigating oils (or even water) using neutron reflectivity, but its nature remains a subject of debate. One explanation is that the oleophobicity of the $\mathrm{SiO}_{2}$ surface creates some form of "nanobubbles" 78 at the surface. Another possible cause would be that any water existing in the solvent phase would naturally migrate to this surface to form a very thin watery layer at the interface. Since hydrogen has a negative scattering length, this would produce a drop in the SLD, and the required amounts of water are in the ppm range and thus very difficult to both measure and eliminate.

The SLD profile presented in Figure 5 is somewhat different from the profiles obtained by Jouault et al. ${ }^{72}$ They report that they could not keep fixed values for the silica oxide layer when fitting the data. However, these authors calculated the SLD profiles from neutron reflectometry data obtained only in Dtoluene. The profile presented in Figure 5 was determined from the simultaneous fit of several data sets measured at different $\mathrm{D}$-toluene/H-toluene ratios that strongly constrained the results.

By integrating the amount of asphaltene in different positions above the surface (as calculated from the SLD profile in Figure 5) and using the known specific mass of asphaltene $\left(1.15 \mathrm{~g} / \mathrm{cm}^{3}\right)$, one obtains a total coverage of 3.0 $\mathrm{mg} / \mathrm{m}^{2}$. This value compares well with the independent results from the QCM measurements presented in section 3.2.1.
Finally, the possibility of a "two-layer" asphaltene model was investigated. Such a situation might occur if the asphaltenes were adsorbed as individual molecules with a specific preference for either the side chains or the aromatic regions being directed toward the surface. However, several variants of two-layer models were tested on the present data, but they always converged with the second layer having zero thickness, independent of the starting values used for hydration and thicknesses of the two layers. This is a strong indication that we do not have a two-layer structure for this system-a situation that can be expected if the asphaltene adsorbs mainly in the form of nanoaggregates already formed in solution and less in the form of individual molecules.

These neutron reflectivity measurements have allowed us to determine the concentration profile of the asphaltene layer in the perpendicular direction with respect to the silicon wafer. The presence and extent of lateral heterogeneities, such as patches or aggregates, cannot be determined from our measurements. Other techniques such as off-specular reflectometry $^{79}$ or atomic force microscopy ${ }^{80}$ should be implemented to get such information.

3.2.4. Influence of Pluronic on the Asphaltene Layer. The values obtained from the contrast variation experiment were subsequently used as initial parameters to analyze the data describing the influence of pluronic on asphaltene adsorption measured at PSI. For these data, it was found that without this prior information about the asphaltene, several solutions could provide nearly similar quality of the fitting, resulting in contradictory descriptions of the asphaltene layer (flat adsorption of asphaltenes with no solvent penetration into the asphaltene (solvation) vs. thicker layers with $90 \%$ solvation for instance). This came from the limited constraint on the fitting since these systems were only measured in D-toluene, and therefore, the parameters were calculated from the fitting of a single curve.

Figure 6 presents the reflectivity curves, given as logarithm of $R Q^{4}$ as a function of $Q$ for asphaltene at $2 \mathrm{~g} / \mathrm{L}$ in D-toluene, asphaltene at $2 \mathrm{~g} / \mathrm{L}+$ pluronic at $0.1 \mathrm{~g} / \mathrm{L}$ in D-toluene, as well

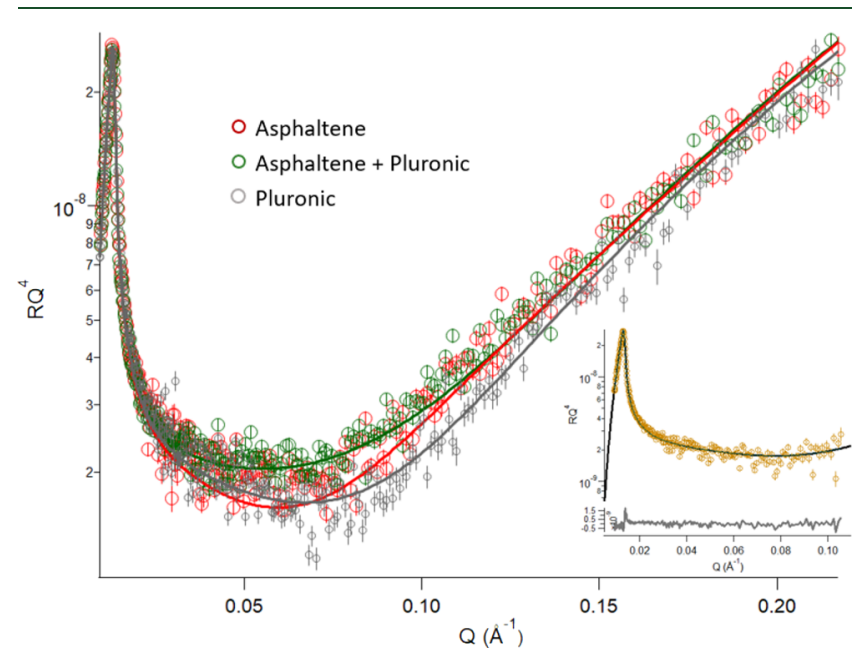

Figure 6. Reflectivity curves, $R Q^{4}$ as a function of $Q$ and model curves (continuous lines) for asphaltenes at $2 \mathrm{~g} / \mathrm{L}$, asphaltenes at $2 \mathrm{~g}$ / $\mathrm{L}+$ pluronic at $0.1 \mathrm{~g} / \mathrm{L}$, and only pluronic at $0.1 \mathrm{~g} / \mathrm{L}$, all in D-toluene. The inset shows the pattern for the silicon wafer in D-toluene. The data has been normalized but not background-subtracted. The model curves include background values used in the fitting. 
as the pattern for pluronic at $0.1 \mathrm{~g} / \mathrm{L}$ in $\mathrm{D}$-toluene. In the figure is also shown as an inset the curve for D-toluene only.

The reflectivity curves in the presence of asphaltenes and/or pluronic present some variations compared with the wafers measured in pure D-toluene. Specifically, there is an added contribution to the reflectivity pattern in the range above ca. $Q$ $=0.05 \AA^{-1}$. This highlights the presence of an adsorbed layer on top of the silicon. There are also some differences in the reflectivity patterns between the investigated systems, which could be used to extract thickness and roughness values by least-squares fitting and compare their variations. As mentioned previously, the methodology used to fit a reflectivity curve measured only in D-toluene without varying the $\mathrm{D}$ toluene/H-toluene ratio is quite critical. It was found that different combinations of parameters, i.e., both low/high solvation vs. high/low thickness and roughness, could give reasonable fits depending on the initial guess entered in the fitting routine. For this reason, the fitting of reflectivity curves obtained in D-toluene was performed using as a reference the parameters calculated previously in the multicontrast study. The fitting of systems containing pluronic was also analyzed by constraining the solvation, assuming a high value $(>90 \%)$ even if these systems were not previously analyzed with the contrast variation method, since their reflectivity variations are relatively close to that of asphaltene. Similarly to what was done in section section 3.2.3, the characteristics of the silicon oxide layer were first determined from the reflectivity curve measured in D-toluene and in the absence of asphaltenes or pluronic. These characteristics were then used as inputs to fit the reflectivity curves in the presence of asphaltenes and/or pluronic. The model curves are included in the plots in Figure 6 , and the characteristics of the adsorbed layer for the different systems are presented in Table 5. It should be noted, however, that the error bars are relatively large for these values due to the fact that this is not a contrast variation study.

Table 5. Thickness, Roughness, and the Solvation Degree for the Various Investigated Systems Obtained by Fitting the Reflectivity Data Presented in Figure $6^{a}$

\begin{tabular}{lccc}
\multicolumn{1}{c}{ system } & $\begin{array}{c}\text { thickness } \\
(\AA)\end{array}$ & $\begin{array}{c}\text { roughness } \\
(\AA)\end{array}$ & $\begin{array}{c}\text { solvation (volume } \\
\text { percent) }\end{array}$ \\
D-toluene $\left(\mathrm{SiO}_{2}\right.$ surface layer $)$ & 13.9 & 7.9 & \\
asphaltenes $(2 \mathrm{~g} / \mathrm{L})$ & 47 & 4 & 94 \\
pluronic $(0.1 \mathrm{~g} / \mathrm{L})$ & 28 & 6 & 92 \\
asphaltenes $(2 \mathrm{~g} / \mathrm{L}){ }_{+}^{+}$ & 39 & 12 & 97
\end{tabular}

asphaltenes $(2 \mathrm{~g} / \mathrm{L})+$

pluronic $(0.1 \mathrm{~g} / \mathrm{L})^{b}$

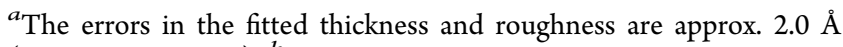
(solvent: D-toluene). ${ }^{b}$ For this sample, the values are more uncertain because the SLD value was also fitted (since the composition ratio between asphaltenes and pluronic inside the layer is not known).

From inspection of Figure 6, the differences are seen to be small, and between asphaltene and the mixture (asphaltene +pluronic), there is only a tiny difference visible in the range below $Q=0.1 \AA^{-1}$. This observation shows directly that the effects of pluronic addition are quite small for this system. Based on the fitting, the pure asphaltene layer was found to have a thickness of ca. 47 Å with a relatively small roughness (4 $\AA$ ). These values are similar to the ones found in the contrast matching experiments. We note that the asphaltene is found to have a high degree of solvation, above $90 \%$. Due to the signalto-noise level of the data, this value cannot be determined very accurately. For the fitting to converge, it was necessary to put limits on the solvation parameter, based on the results from the contrast variation experiment presented in the previous section.

The pluronic layer was found to have a smaller thickness of ca. $28 \AA$ A with a roughness of $6 \AA$. A size of $28 \AA$ is equivalent to $18 \mathrm{C}-\mathrm{C}$ single bonds. Therefore, considering the molecular weight of the pluronic $\left(2600 \mathrm{~g} / \mathrm{mol}^{55}\right)$, equivalent to $186 \mathrm{C}-\mathrm{C}$ bonds, that means that the pluronic chains are not protruding very far into the solvent and adopt a relatively flat conformation on silicon oxide. Shar et al. obtained similar conclusions by measuring the hydrodynamic thickness of pluronic adsorbed on silica particles in aqueous solution. ${ }^{71} \mathrm{We}$ note that the relative size of the pluronic layer with respect to that of the asphaltene $(28 \AA / 47 \AA)$ is quite close to the ratio of the adsorbed amount of these compounds as found from the QCM data, indicating that the reflectometry and QCM experiments are comparable.

The layer formed with a mixed solution of asphaltenes and pluronic presents a slightly shorter layer thickness (39 ̊) than the pure asphaltene layer. This reduction indicates that the pluronic is partially incorporated into the asphaltene layer although the interaction is weak. The percentage reduction of the thickness $(17 \%)$ is in good agreement with the reduction of the adsorbed amount when pluronic is present, as found from QCM (19\%).

It should be noted that for the mixed system of asphaltene and pluronic, the SLD was fitted to an approximate value of 1.2 $\times 10^{-6} \AA^{-2}$. This SLD is slightly lower than that of asphaltene $\left(1.32 \times 10^{-6} \AA^{-2}\right)$ and much higher than that of pure pluronic $\left(0.5 \times 10^{-6} \AA^{-2}\right)$. This difference demonstrates that the pluronic is only weakly incorporated into the asphaltene layer. The roughness of $12 \AA$ found for this mixed layer (cf. Table 5) is a coarse value, i.e., with quite large uncertainty, due to the limited information content of the data when the exact SLD of the layer is not known a priori.

\section{CONCLUSIONS}

The use of two different neutron scattering techniques, SANS and neutron reflectometry, made it possible to study the behavior of the same source of asphaltenes both in solution (bulk) and when adsorbed onto a solid surface. The bulk measurements demonstrated that these asphaltenes tend to form nanoaggregates when dissolved in D-toluene, with an overall diameter of around $6 \mathrm{~nm}$.

The reflectometry studies were performed using a contrast variation technique, whereby a series of $\mathrm{D}$-toluene/H-toluene ratios were employed to change the scattering contrast between the solvent, the solid surface, and the adsorbed layer. This methodology turned out to be crucial to extract reliable values for the adsorbed asphaltene, particularly due to the high degree of solvent penetration for this asphaltene. An asphaltene thickness of $51 \AA$ and roughness of $7 \AA$, as well as an average solvation of $91 \%$, was found in this study. This asphaltene thickness corroborates a situation where nanoaggregates from the solution adsorb onto the silicon surfacepossibly due to some unshielded polar entities interacting with the hydrophilic surface, as shown by dissipative particle dynamics (DPD) simulation results ${ }^{81}$ - and where the aggregates become moderately compressed in the process. The high degree of solvation is in accord with indirect results obtained by Jestin et al. on a different asphaltene source. On the other hand, one cannot exclude that this value, which is an 
average over the surface, might be due partly to some areas not being fully covered by asphaltene (thus containing mainly solvent). Such a situation will also affect the average surface roughness that was measured here to be $7 \AA$. It should furthermore be noted that the SLD curve extracted from the fitting indicates a lower degree of solvation of the asphaltene close to the surface.

Finally, the adsorption onto a hydrophilic surface of the model demulsifier pluronic in combination with asphaltene was studied. The pluronic alone shows a significantly weaker surface adsorption than asphaltene. Furthermore, when pluronic is added $(0.1 \mathrm{~g} / \mathrm{L})$, the thickness of the adsorbed asphaltene layer is reduced by approximately $17 \%$, showing the demulsifying effect of pluronic. These results were also in good accordance with data obtained independently from QCM measurements.

To conclude, this study has provided a better description of the properties of the asphaltene layer and the effect of a model demulsifier on it. As far as the authors of the present study are concerned, this description could be used to constrain models aiming to simulate crude oil interfaces ${ }^{82}$ to understand and improve the oil-water separation process in the crude oil industry.

\section{ASSOCIATED CONTENT}

\section{(s) Supporting Information}

The Supporting Information is available free of charge at https://pubs.acs.org/doi/10.1021/acs.energyfuels.9b03831.

SANS data for asphaltenes at $2.5 \mathrm{~g} / \mathrm{L}$ in D-toluene (PDF)

\section{AUTHOR INFORMATION}

\section{Corresponding Author}

Sébastien Simon - Ugelstad Laboratory, Department of

Chemical Engineering, the Norwegian University of Science and Technology (NTNU), N-7491 Trondheim, Norway; ๑ orcid.org/0000-0002-3101-4267; Phone: $(+47) 735916$ 57; Email: sebastien.simon@chemeng.ntnu.no; Fax: (+47) 73594080

\section{Authors}

Kenneth D. Knudsen - Institute for Energy Technology (IFE), N-2007 Kjeller, Norway; Department of Physics, the Norwegian University of Science and Technology (NTNU), N-7491 Trondheim, Norway

Thomas Geue - Laboratory for Neutron Scattering and Imaging (LNS), Paul Scherrer Institute, CH-5232 Villigen, Switzerland

Joshaniel F. K. Cooper - Science and Technology Facilities Council, Rutherford Appleton Laboratory, Harwell Science and Innovation Campus, ISIS Neutron and Muon Source, Oxon OX11 0QX, United Kingdom

Johan Sjöblom - Ugelstad Laboratory, Department of Chemical Engineering, the Norwegian University of Science and Technology (NTNU), N-7491 Trondheim, Norway

Complete contact information is available at:

https://pubs.acs.org/10.1021/acs.energyfuels.9b03831

\section{Notes}

The authors declare no competing financial interest.

\section{ACKNOWLEDGMENTS}

The authors thank the JIP Electrocoalesence Consortium, "New Strategy for Separation of Complex Water-in-Crude Oil Emulsions: From Bench to Large Scale Separation", consisting of Ugelstad Laboratory (NTNU, Norway), University of Alberta (Canada), Swiss Federal Institute of Technology in Zurich (Switzerland), and Institute for Energy Technology (IFE, Norway) and funding by the Norwegian Research Council (Petromaks II Grant 255174) and the following industrial sponsors: Anvendt Teknologi AS, Equinor, NalcoChampion, Nouryon, and Sulzer. This work is based on experiments performed at the Swiss spallation neutron source SINQ, Paul Scherrer Institute, Villigen PSI, Switzerland and at the ISIS Neutron and Muon Source, UK. Experiments at SINQ were supported by beam time allocation 20170059. Experiments at the ISIS Neutron and Muon Source were supported by a beam time allocation RB1820191 from the Science and Technology Facilities Council (DOI: 10.5286/ISIS.E. 98000988). The authors thank Einar Eng Johnsen (Equinor) for his comments on the manuscript.

\section{REFERENCES}

(1) Fakhru'l-Razi, A.; Pendashteh, A.; Abdullah, L. C.; Biak, D. R. A.; Madaeni, S. S.; Abidin, Z. Z. Review of technologies for oil and gas produced water treatment. J. Hazard. Mater. 2009, 170, 530-551.

(2) Eow, J. S.; Ghadiri, M. Electrostatic enhancement of coalescence of water droplets in oil: a review of the technology. Chem. Eng. J. 2002, 85, 357-368.

(3) Eow, J. S.; Ghadiri, M.; Sharif, A. O.; Williams, T. J. Electrostatic enhancement of coalescence of water droplets in oil: a review of the current understanding. Chem. Eng. J. 2001, 84, 173-192.

(4) Less, S.; Hannisdal, A.; Bjørklund, E.; Sjöblom, J. Electrostatic destabilization of water-in-crude oil emulsions: Application to a real case and evaluation of the Aibel VIEC technology. Fuel 2008, 87, 2572-2581.

(5) Al-Sabagh, A. M.; Kandile, N. G.; Noor El-Din, M. R. Functions of Demulsifiers in the Petroleum Industry. Sep. Sci. Technol. 2011, 46, 1144-1163.

(6) Sjöblom, J.; Aske, N.; Auflem, I. H.; Brandal, Ø.; Havre, T. E.; Saether, Ø.; Westvik, A.; Johnsen, E. E.; Kallevik, H. Our Current Understanding of Water-in-Crude Oil Emulsions.: Recent Characterization Techniques and High Pressure Performance. Adv. Colloid Interface Sci. 2003, 100-102, 399-473.

(7) Grutters, M.; van Dijk, M.; Dubey, S.; Adamski, R.; Gelin, F.; Cornelisse, P. Asphaltene Induced W/O Emusilon: False or True? J. Dispersion Sci. Technol. 2007, 28, 357-360.

(8) Sjöblom, J.; Simon, S.; Xu, Z. Model molecules mimicking asphaltenes. Adv. Colloid Interface Sci. 2015, 218, 1-16.

(9) Hanneseth, A.-M. D.; Selsbak, C.; Sjöblom, J. Behavior and Stability of Naphthenic Acid/Naphthenate Stabilized Emulsions. Mixed C80-Tetraacid and Stearic Acid Stabilization. J. Dispersion Sci. Technol. 2010, 31, 770-779.

(10) Arla, D.; Sinquin, A.; Palermo, T.; Hurtevent, C.; Graciaa, A.; Dicharry, C. Influence of $\mathrm{pH}$ and Water Content on the Type and Stability of Acidic Crude Oil Emulsions. Energy Fuels 2007, 21, 13371342.

(11) Ese, M. H.; Kilpatrick, P. K. Stabilization of Water-in-Oil Emulsions by Naphthenic Acids and Their Salts: Model Compounds, Role of $\mathrm{pH}$, and Soap:Acid Ratio. J. Dispersion Sci. Technol. 2004, 25, 253-261.

(12) Sullivan, A. P.; Kilpatrick, P. K. The Effects of Inorganic Solid Particles on Water and Crude Oil Emulsion Stability. Ind. Eng. Chem. Res. 2002, 41, 3389-3404.

(13) Hannisdal, A.; Ese, M.-H.; Hemmingsen, P. V.; Sjöblom, J. Particle-stabilized emulsions: Effect of heavy crude oil components 
pre-adsorbed onto stabilizing solids. Colloids Surf., A 2006, 276, 4558.

(14) Kralova, I.; Sjöblom, J.; Øye, G.; Simon, S.; Grimes, B. A.; Paso, K. Heavy Crude Oils/Particle Stabilized Emulsions. Adv. Colloid Interface Sci. 2011, 169, 106-127.

(15) Speight, J. G. Petroleum Asphaltenes - Part 1: Asphaltenes, Resins and the Structure of Petroleum. Oil Gas Sci. Technol. 2004, 59, 467-477.

(16) Subramanian, S.; Simon, S.; Gao, B.; Sjöblom, J. Asphaltene fractionation based on adsorption onto calcium carbonate: Part 1 . Characterization of sub-fractions and QCM-D measurements. Colloids Surf., A 2016, 495, 136-148.

(17) Subramanian, S.; Sørland, G. H.; Simon, S.; Xu, Z.; Sjöblom, J. Asphaltene fractionation based on adsorption onto calcium carbonate: Part 2. Self-association and aggregation properties. Colloids Surf., A 2017, 514, 79-90.

(18) Groenzin, H.; Mullins, O. C. Asphaltene Molecular Size and Structure. J. Phys. Chem. A 1999, 103, 11237-11245.

(19) Groenzin, H.; Mullins, O. C. Molecular Size and Structure of Asphaltenes from Various Sources. Energy Fuels 2000, 14, 677-684.

(20) Groenzin, H.; Mullins, O. C. Molecular Size and Structure of Asphaltenes. Pet. Sci. Technol. 2007, 19, 219-230.

(21) Groenzin, H.; Mullins, O. C.; Eser, S.; Mathews, J.; Yang, M. G.; Jones, D. Molecular Size of Asphaltene Solubility Fractions. Energy Fuels 2003, 17, 498-503.

(22) Hortal, A. R.; Martínez-Haya, B.; Lobato, M. D.; Pedrosa, J. M.; Lago, S. On the determination of molecular weight distributions of asphaltenes and their aggregates in laser desorption ionization experiments. J. Mass Spectrom. 2006, 41, 960-968.

(23) Pomerantz, A. E.; Hammond, M. R.; Morrow, A. L.; Mullins, O. C.; Zare, R. N. Two-Step Laser Mass Spectrometry of Asphaltenes. J. Am. Chem. Soc. 2008, 130, 7216-7217.

(24) Pomerantz, A. E.; Hammond, M. R.; Morrow, A. L.; Mullins, O. C.; Zare, R. N. Asphaltene Molecular-Mass Distribution Determined by Two-Step Laser Mass Spectrometry. Energy Fuels 2009, 23, 11621168.

(25) Mitra-Kirtley, S.; Mullins, O. C.; Van Elp, J.; George, S. J.; Chen, J.; Cramer, S. P. Determination of the nitrogen chemical structures in petroleum asphaltenes using XANES spectroscopy. J. Am. Chem. Soc. 1993, 115, 252-258.

(26) Simon, S.; Nenningstand, A. L.; Herschbach, E.; Sjöblom, J. Extraction of Basic Components from Petroleum Crude Oil. Energy Fuels 2010, 24, 1043-1050.

(27) Speight, J. G. The Chemistry and Technology of Petroleum; 4th Edition, CRC Press, 2007.

(28) Murgich, J. Molecular Simulation and the Aggregation of the Heavy Fractions in Crude Oils. Mol. Simul. 2003, 29, 451-461.

(29) Schuler, B.; Meyer, G.; Peña, D.; Mullins, O. C.; Gross, L. Unraveling the Molecular Structures of Asphaltenes by Atomic Force Microscopy. J. Am. Chem. Soc. 2015, 137, 9870-9876.

(30) Mullins, O. C. The Modified Yen Model. Energy Fuels 2010, 24, 2179-2207.

(31) Chacón-Patiño, M. L.; Rowland, S. M.; Rodgers, R. P. Advances in Asphaltene Petroleomics. Part 3. Dominance of Island or Archipelago Structural Motif Is Sample Dependent. Energy Fuels 2018, 32, 9106-9120.

(32) Fenistein, D.; Barre, L.; Frot, D. From Aggregation to Flocculation of Asphaltenes, a Structural Description by Radiation Scattering Techniques. Oil Gas Sci. Technol. 2000, 55, 123-128.

(33) Anisimov, M. A.; Yudin, I. K.; Nikitin, V.; Nikolaenko, G.; Chernoutsan, A.; Toulhoat, H.; Frot, D.; Briolant, Y. Asphaltene Aggregation in Hydrocarbon Solutions Studied by Photon Correlation Spectroscopy. J. Phys. Chem. 1995, 99, 9576-9580.

(34) Wang, X.; Zhang, R.; Liu, L.; Qiao, P.; Simon, S.; Sjöblom, J.; $\mathrm{Xu}, \mathrm{Z}$.; Jiang, B. Interactions of Polyaromatic Compounds. Part 2. Flocculation Probed by Dynamic Light Scattering and Molecular Dynamics Simulation. Energy Fuels 2017, 31, 9201-9212.
(35) Eyssautier, J.; Frot, D.; Barré, L. Structure and Dynamic Properties of Colloidal Asphaltene Aggregates. Langmuir 2012, 28, 11997-12004.

(36) Barré, L.; Simon, S.; Palermo, T. Solution Properties of Asphaltenes. Langmuir 2008, 24, 3709-3717.

(37) Espinat, D.; Fenistein, D.; Barré, L.; Frot, D.; Briolant, Y. Effects of Temperature and Pressure on Asphaltenes Agglomeration in Toluene. A Light, X-ray, and Neutron Scattering Investigation. Energy Fuels 2004, 18, 1243-1249.

(38) Fenistein, D.; Barré, L. Experimental measurement of the mass distribution of petroleum asphaltene aggregates using ultracentrifugation and small-angle X-ray scattering. Fuel 2001, 80, 283-287.

(39) Fenistein, D.; Barré, L.; Broseta, D.; Espinat, D.; Livet, A.; Roux, J. N.; Scarsella, M. Viscosimetric and Neutron Scattering Study of Asphaltene Aggregates in Mixed Toluene/Heptane Solvents. Langmuir 1998, 14, 1013-1020.

(40) Simon, S.; Jestin, J.; Palermo, T.; Barré, L. Relation between Solution and Interfacial Properties of Asphaltene Aggregates. Energy Fuels 2009, 23, 306-313.

(41) Spiecker, P. M.; Gawrys, K. L.; Kilpatrick, P. K. Aggregation and solubility behavior of asphaltenes and their subfractions. J. Colloid Interface Sci. 2003, 267, 178-193.

(42) Spiecker, P. M.; Gawrys, K. L.; Trail, C. B.; Kilpatrick, P. K. Effects of petroleum resins on asphaltene aggregation and water-in-oil emulsion formation. Colloids Surf., A 2003, 220, 9-27.

(43) Roux, J.-N.; Broseta, D.; Demé, B. SANS Study of Asphaltene Aggregation: Concentration and Solvent Quality Effects. Langmuir 2001, 17, 5085-5092.

(44) Fossen, M.; Kallevik, H.; Knudsen, K. D.; Sjöblom, J. Asphaltenes Precipitated by a Two-Step Precipitation Procedure. 1 . Interfacial Tension and Solvent Properties. Energy Fuels 2007, 21, 1030-1037.

(45) Dickie, J. P.; Yen, T. F. Macrostructures of the asphaltic fractions by various instrumental methods. Anal. Chem. 1967, 39, $1847-1852$.

(46) Mullins, O. C.; Sabbah, H.; Eyssautier, J.; Pomerantz, A. E.; Barré, L.; Andrews, A. B.; Ruiz-Morales, Y.; Mostowfi, F.; McFarlane, R.; Goual, L.; Lepkowicz, R.; Cooper, T.; Orbulescu, J.; Leblanc, R. M.; Edwards, J.; Zare, R. N. Advances in Asphaltene Science and the Yen-Mullins Model. Energy Fuels 2012, 26, 3986-4003.

(47) Pfeiffer, J. P.; Saal, R. N. J. Asphaltic bitumen as colloid system. J. Phys. Chem. 1940, 44, 139-149.

(48) Eyssautier, J.; Levitz, P.; Espinat, D.; Jestin, J.; Gummel, J.; Grillo, I.; Barré, L. Insight into Asphaltene Nanoaggregate Structure Inferred by Small Angle Neutron and X-ray Scattering. J. Phys. Chem. B 2011, 115, 6827-6837.

(49) Subramanian, S.; Simon, S.; Sjöblom, J. Interaction between asphaltenes and fatty-alkylamine inhibitor in bulk solution. $J$. Dispersion Sci. Technol. 2017, 39, 163-173.

(50) Teklebrhan, R. B.; Ge, L.; Bhattacharjee, S.; Xu, Z.; Sjöblom, J. Probing Structure-Nanoaggregation Relations of Polyaromatic Surfactants: A Molecular Dynamics Simulation and Dynamic Light Scattering Study. J. Phys. Chem. B 2012, 116, 5907-5918.

(51) Jian, C.; Tang, T.; Bhattacharjee, S. Probing the Effect of SideChain Length on the Aggregation of a Model Asphaltene Using Molecular Dynamics Simulations. Energy Fuels 2013, 27, 2057-2067.

(52) Jestin, J.; Simon, S.; Zupancic, L.; Barré, L. A Small Angle Neutron Scattering Study of the Adsorbed Asphaltene Layer in Water-in-Hydrocarbon Emulsions: Structural Description Related to Stability. Langmuir 2007, 23, 10471-10478.

(53) Verruto, V. J.; Kilpatrick, P. K. Water-in-Model Oil Emulsions Studied by Small-Angle Neutron Scattering: Interfacial Film Thickness and Composition. Langmuir 2008, 24, 12807-12822.

(54) Kelland, M. A. Production Chemicals for the Oil and Gas Industry; 2nd Edition CRC Press, 2014; p 454.

(55) BASF. Pluronic PE types. Technical Information TI/ES $1026 e$; BASF, 1996. 
(56) Adachi, S.; Utani, K. Chemical Treatment Effects of Si Surfaces in NH4OH:H2O2:H2O Solutions Studied by Spectroscopic Ellipsometry. Jpn. J. Appl. Phys. 1993, 32, L1189-L1191.

(57) Clemens, D.; Gross, P.; Keller, P.; Schlumpf, N.; Könnecke, M. AMOR - the versatile reflectometer at SINQ. Phys. B 2000, 276-278, $140-141$.

(58) Nelson, A. Analysis of multiple contrast X-ray and Neutron Reflectometry data - Motofit mode, Revision 409; 2009.

(59) IGOR Pro, Version 6.37; Wavemetrics Inc, 2014.

(60) Bjorck, M. GenX, 2008.

(61) Névot, L.; Croce, P. Caractérisation des surfaces par réflexion rasante de rayons X. Application à l'étude du polissage de quelques verres silicates. Rev. Phys. Appl. 1980, 15, 761-779.

(62) Cousin, F.; Menelle, A. Neutron reflectivity. EPJ Web Conf. 2015, 104, No. 01005.

(63) Sauerbrey, G. Verwendung von Schwingquarzen zur Wägung dünner Schichten und zur Mikrowägung. J. Phys. 1959, 155, 206-222.

(64) Pedersen, J. S. Analysis of small-angle scattering data from colloids and polymer solutions: modeling and least-squares fitting. Adv. Colloid Interface Sci. 1997, 70, 171-210.

(65) Gawrys, K. L.; Kilpatrick, P. K. Asphaltenic aggregates are polydisperse oblate cylinders. J. Colloid Interface Sci. 2005, 288, 325334.

(66) Gawrys, K. L.; Blankenship, G. A.; Kilpatrick, P. K. Solvent Entrainment in and Flocculation of Asphaltenic Aggregates Probed by Small-Angle Neutron Scattering. Langmuir 2006, 22, 4487-4497.

(67) Hoepfner, M. P.; Fogler, H. S. Multiscale Scattering Investigations of Asphaltene Cluster Breakup, Nanoaggregate Dissociation, and Molecular Ordering. Langmuir 2013, 29, 1542315432 .

(68) Hoepfner, M. P.; Vilas Bôas Fávero, C.; Haji-Akbari, N.; Fogler, H. S. The Fractal Aggregation of Asphaltenes. Langmuir 2013, 29, 8799-8808.

(69) Simon, S.; Knudsen, K. D.; Nordgård, E.; Reisen, C.; Sjöblom, J. Aggregation of tetrameric acids in aqueous media studied by smallangle neutron scattering. J. Colloid Interface Sci. 2013, 394, 277-283.

(70) Pradilla, D.; Subramanian, S.; Simon, S.; Sjöblom, J.; Beurroies, I.; Denoyel, R. Microcalorimetry Study of the Adsorption of Asphaltenes and Asphaltene Model Compounds at the LiquidSolid Surface. Langmuir 2016, 32, 7294-7305.

(71) Shar, J. A.; Obey, T. M.; Cosgrove, T. Adsorption studies of polyethers: Part II: adsorption onto hydrophilic surfaces. Colloids Surf., A 1999, 150, 15-23.

(72) Jouault, N.; Corvis, Y.; Cousin, F.; Jestin, J.; Barré, L. Asphaltene Adsorption Mechanisms on the Local Scale Probed by Neutron Reflectivity: Transition from Monolayer to Multilayer Growth above the Flocculation Threshold. Langmuir 2009, 25, 3991-3998.

(73) Corvis, Y.; Barré, L.; Jestin, J.; Gummel, J.; Cousin, F. Asphaltene adsorption mechanism under shear flow probed by in situ neutron reflectivity measurements. Eur. Phys. J. Spec. Top. 2012, 213, 295-302.

(74) Fragneto, G.; Lu, J. R.; McDermott, D. C.; Thomas, R. K.; Rennie, A. R.; Gallagher, P. D.; Satija, S. K. Structure of Monolayers of Tetraethylene Glycol Monododecyl Ether Adsorbed on SelfAssembled Monolayers on Silicon: A Neutron Reflectivity Study. Langmuir 1996, 12, 477-486.

(75) Penfold, J.; Staples, E. J.; Tucker, I.; Thompson, L. J.; Thomas, R. K. The structure and composition of mixed cationic and non-ionic surfactant layers adsorbed at the hydrophilic silicon surface. Phys. $B$ 1998, 248, 223-228.

(76) Wang, J.; van der Tuuk Opedal, N.; Lu, Q.; Xu, Z.; Zeng, H.; Sjöblom, J. Probing Molecular Interactions of an Asphaltene Model Compound in Organic Solvents Using a Surface Forces Apparatus (SFA). Energy Fuels 2012, 26, 2591-2599.

(77) Sztukowski, D. M.; Jafari, M.; Alboudwarej, H.; Yarranton, H. W. Asphaltene self-association and water-in-hydrocarbon emulsions. J. Colloid Interface Sci. 2003, 265, 179-186.
(78) Gutfreund, P.; Maccarini, M.; Dennison, A. J. C.; Wolff, M. The Search for Nanobubbles by Using Specular and Off-Specular Neutron Reflectometry. Langmuir 2016, 32, 9091-9096.

(79) Pynn, R.; Baker, S.; Smith, G.; Fitzsimmons, M. Off-specular scattering in neutron reflectometry. J. Neutron Res. 1999, 7, 139-158.

(80) Manne, S.; Schäffer, T. E.; Huo, Q.; Hansma, P. K.; Morse, D. E.; Stucky, G. D.; Aksay, I. A. Gemini Surfactants at Solid-Liquid Interfaces: Control of Interfacial Aggregate Geometry. Langmuir 1997, 13, 6382-6387.

(81) Skartlien, R.; Simon, S.; Sjöblom, J. DPD Molecular Simulations of Asphaltene Adsorption on Hydrophilic Substrates: Effects of Polar Groups and Solubility. J. Dispersion Sci. Technol. 2016, 37, 866-883.

(82) Kuznicki, T.; Masliyah, J. H.; Bhattacharjee, S. Aggregation and Partitioning of Model Asphaltenes at Toluene-Water Interfaces: Molecular Dynamics Simulations. Energy Fuels 2009, 23, 5027-5035. 